\title{
Free Fatty Acid Metabolism
}

\section{of the Human Heart at Rest}

\author{
Albert S. Most, Norman Brachfeld, Ruchard Gorlin, and \\ JOHN WAHREN
}

From the Cardiovascular Division, Department of Medicine, Peter Bent

Brigham Hospital, Harvard Medical School, Boston, Massachusetts 02115;

Department of Medicine, Cornell University Medical College, New York 10021;

and Institute for Muscle Disease, Inc., New York 10021

A B S T R A C T Myocardial substrate metabolism was studied in 13 subjects at the time of diagnostic cardiac catheterization by means of palmitic acid- ${ }^{14} \mathrm{C}$ infusion with arterial and coronary sinus sampling. Two subjects were considered free of cardiac pathology and all, with one exception, demonstrated lactate extraction across the portion of heart under study. Data for this single lactate-producing subject were treated separately.

The fractional extraction of ${ }^{14} \mathrm{C}$-labeled free fatty acids (FFA) $(44.4 \pm 9.5 \%)$ was nearly twice that of unlabeled FFA $(23.2 \pm 7.8 \%)$ and raised the possibility of release of FFA into the coronary sinus. FFA uptake, based on either the arterial minus coronary sinus concentration difference or the FFA $-{ }^{14} \mathrm{C}$ fractional extraction, was directly proportional to the arterial FFA concentration. Gas-liquid chromatography failed to demonstrate selective handling of any individual FFA by the heart. Fractional oxidation of FFA was $53.5 \pm 12.7 \%$, accounting for $53.2 \pm 14.4 \%$ of the heart's oxygen consumption while nonlipid substrates accounted for an additional $30.0 \pm 17.3 \%$. Determinations of both labeled and unlabeled triglycerides suggested utilization of this substrate by the fasting human heart.

Direct measurement of FFA fractional oxidation as well as FFA uptake, exclusive of possible simultaneous FFA release, would appear necessary in studies concerned with human myocardial FFA metabolism.

\section{INTRODUCTION}

Since the first demonstration that fatty acids (1), and more specifically free fatty acids (FFA) bound to serum albumin (2), can serve as a substrate in human

A preliminary report of part of this work has appeared in abstract form in 1968 Circulation. 38 (Suppl. 6) : 142.

Received for publication 18 October 1968 and in revised form 4 February 1969. myocardial metabolism, numerous investigations have confirmed this observation (3-7). In addition, it has been established that plasma FFA are the major myocardial substrate in the postabsorptive state in man $(3,8,9)$. The arteriovenous concentration difference bears a direct but variable and as yet poorly understood relationship to the arterial concentration (3). The extraction ratios vary slightly for individual fatty acids and may be influenced by the length of the carbon chain and the number of double bonds $(7,10)$. These results have been obtained on the basis of arterial and coronary sinus concentration differences of FFA in humans, while information regarding the contribution of FFA to myocardial oxidative metabolism has been derived entirely from animal experiments. Albumin-bound ${ }^{14} \mathrm{C}$-labeled FFA have been used in the study of myocardial oxidation of FFA in the intact dog heart, as well as in isolated heart preparations (11). In man, such isotope techniques have been described in studies of uptake and oxidation of FFA by skeletal muscle. Findings in the human forearm and leg indicate that simple measurements of the arteriovenous difference of unlabeled FFA may not always accurately reflect true tissue uptake and utilization $(12,13)$. In the present study, isotope techniques have been utilized in man to define more clearly myocardial uptake and metabolism of FFA in the resting state. It has been shown that the fractional extraction of $\mathrm{FFA}-{ }^{14} \mathrm{C}$ is greater than that of unlabeled FFA, that the fractional oxidation of $\mathrm{FFA}-{ }^{14} \mathrm{C}$ is approximately $55 \%$, and that FFA oxidation accounts for a little over half of the heart's oxygen consumption. Oxidative metabolism of the human heart is discussed on the basis of these findings.

\section{METHODS}

All 13 subjects were admitted to the hospital and studied after an overnight fast $(>14 \mathrm{hr})$ immediately before diag- 
nostic cardiac catheterization. All subjects were over $40 \mathrm{yr}$ of age and had given informed consent for this metabolic study. Clinical data and catheterization findings are summarized in Table $I$.

A premedication consisting of intramuscular sodium pentobarbital $(100 \mathrm{mg})$ and meperidine $(50 \mathrm{mg})$ was administered approximately $2 \mathrm{hr}$ before the metabolic study. A small polyethylene catheter was inserted percutaneously into the brachial artery and a No. 8 Goodale-Lubin catheter was placed in the coronary sinus. Neither glucose nor heparin was administered during the study. Catheters were kept patent by intermittent flushing or slow intravenous infusion of $0.5 \%$ sodium citrate in isotonic saline.

Each subject received $50 \mu \mathrm{c}$ of 1 -palmitate $-{ }^{14} \mathrm{C}$ with a constant infusion pump into a peripheral vein over a predetermined period of $20-60 \mathrm{~min}$. Paired multiple arterial and coronary sinus blood samples were collected at 5-min intervals both during and after the infusion of labeled palmitate for analyses of blood gases and metabolites.

In five subjects coronary blood flow was measured by selective injection of ${ }^{183} \mathrm{Xe}$ into the left coronary artery as soon as metabolic sampling had been completed (14). Precordial ${ }^{133} \mathrm{Xe}$ activity was recorded for $15 \mathrm{~min}$ by an external scintillation detector. This was followed by complete right- and left-sided cardiac catheterization in all cases and selective coronary arteriography in all subjects except one (V. A.).

The albumin-1-palmitate- ${ }^{14} \mathrm{C}$ complex was prepared as follows: 1-palmitic acid- ${ }^{14} \mathrm{C}$ in benzene solution was obtained from New England Nuclear Corp., Boston, Mass. (specific radioactivity $10 \mathrm{mc} / \mathrm{mmole}$ ). $5 \mu$ moles of palmitic acid were transferred into a sterile round-bottomed flask and neutralized with a slight excess of $0.01 \mathrm{~N} \mathrm{KOH}$ in methanol. The mixture was then evaporated to dryness, the potas- sium salt of the fatty acid dissolved in $10 \mathrm{ml}$ of $25 \%$ human serum albumin solution (courtesy of Blood Research Institute, Boston, Mass.), and the mixture filtered through a bacteriologic filter (pore size $0.45 \mu$; Millipore, Bedford, Mass.). The final, postfiltration solution had a specific activity approximating $5 \times 10^{5} \mathrm{dpm} / \mu$ mole $F F A$. The molar ratio postfiltration of FFA to albumin was 1.4 . The albuminFFA solution was subsequently diluted with isotonic saline to a volume of $20-30 \mathrm{ml}$ for intravenous infusion.

Iced, heparinized blood samples for determination of FFA, FFA ${ }^{14} \mathrm{C}$, and other lipid fractions and samples for determination of ${ }^{14} \mathrm{CO}_{2}$ were analyzed within $24 \mathrm{hr}$. Storage for $24 \mathrm{hr}$ was found to increase FFA concentration by approximately $5 \%$. No attempt has been made to correct the data for this increment. FFA concentration was determined by titration according to Dole and Meinertz (15), as modified by Trout, Estes, and Friedberg, utilizing a Nile blue indicator (16). Seven replicate determinations were performed on human serum with a $2.3 \%$ coefficient of variation. FFA composition was analyzed by gas-liquid chromatography after methylation of a lipid extract with diazomethane. During methylation the solution was kept at $0^{\circ} \mathrm{C}$ for $10 \mathrm{~min}$ and then warmed under a stream of nitrogen until colorless. The methyl esters were dissolved in hexane and loaded onto a column of $10 \%$ diethylene glycol succinate (GP 35C D.E.G.S.) on Anakron 80/90 mesh (Jarrel-Ash Co., Waltham, Mass.). A Biomedical Gas Chromatograph (model 400, F. \& M. Scientific Corp., Avondale, Pa.) with a flame ionization detector was used (Hewlett-Packard Co., Lexington, Mass.). The following gas chromatography conditions were employed: carrier gas helium, oven temperature $240^{\circ} \mathrm{C}$, detector temperature $200^{\circ} \mathrm{C}$. The composition of the FFA methyl ester mixture was calculated by photocopying the graphs, cutting out the peaks, and weighing. Reproducibility

TABLE I

Clinical Data and Catheterization Findings

\begin{tabular}{|c|c|c|c|c|c|c|c|}
\hline Subject & Age & Sex & $\begin{array}{l}\text { History } \\
\text { of } \\
\text { angina }\end{array}$ & $\begin{array}{l}\text { History } \\
\text { of } \\
\text { myocar- } \\
\text { dial in- } \\
\text { farction }\end{array}$ & $\underset{\mathrm{K}}{\text { IVGTT }}$ & $\mathrm{CBF}$ & Diagnosis \\
\hline & $y r$ & & & & & $\begin{array}{c}c c / 100 \\
\text { gm per } \\
\text { min }\end{array}$ & \\
\hline B. C. & 50 & $\mathrm{~F}$ & + & - & 0.77 & 57.0 & $\mathrm{CAD}^{*}$ \\
\hline J. G. & 58 & $\mathbf{M}$ & $?$ & - & 1.00 & 74.5 & $\mathrm{CAD}^{*}$ \\
\hline M. F. & 45 & $\mathrm{~F}$ & + & - & 1.39 & 86.0 & CAD* \\
\hline V.A. & 46 & $\mathbf{M}$ & + & + & - & - & CAD \\
\hline J. H. & 73 & $\mathbf{M}$ & + & + & 0.95 & 65.0 & $\mathrm{CAD}^{*}$ \\
\hline J. T. & 64 & $\mathbf{M}$ & $?$ & - & - & - & Mitral stenosis, CAD* \\
\hline P. D. & 60 & $\mathbf{M}$ & + & - & 1.62 & - & $\mathrm{CAD}^{*}$ \\
\hline W. T. & 49 & M & + & + & - & 64.0 & $\mathrm{CAD}^{*}$ \\
\hline A. $R$. & 55 & M & + & $?$ & 0.73 & - & Mitral insufficiency, etiology unknown \\
\hline J. M. & 42 & M & $?$ & - & 1.20 & 一 & Paroxysmal arrhythmia \\
\hline E. C. & 44 & $\mathrm{~F}$ & $?$ & - & 1.25 & - & Probable normal \\
\hline G. M. & 50 & $\mathbf{M}$ & - & - & 1.00 & - & Probable normal \\
\hline T. F. & 67 & $\mathrm{~F}$ & + & + & - & 一 & Mitral stenosis, CAD, ${ }^{*}$ and diabetes mellitus \\
\hline
\end{tabular}

Abbreviations: IVGTT K = glucose decay rate during i.v. glucose tolerance test (IVGTT); CBF = coronary blood flow; CAD $=$ coronary artery disease.

* Demonstrated angiographically.

$\ddagger$ Developed acute myocardial infarction just before coronary angiography. 
of percentage composition by this method is within $10 \%$ for a given value.

Triglyceride concentration was determined by a modification of the method of Van Handel and Zilversmit (17). Nine replicate determinations on human serum gave a $3.2 \%$ coefficient of variation. Plasma samples were extracted with chloroform-methanol, 2:1 (v/v) (18), and aliquots of the extracts were counted for total lipid radioactivity. Lipid fractions were then separated by thin-layer silicic acid chromatography and radioactivity in each fraction determined according to Goldrick and Hirsch (19). A perchloric acid blood extract for determination of lactate, beta hydroxybutyrate and acetoacetate was prepared by precipitation of the proteins with perchloric acid and neutralization of an aliquot of the supernatant with potassium carbonate. Total nonlipid radioactivity of blood was determined on the extract. Determinations of radioactivity were made in a 2,5-diphenyloxazole (PPO)-p-bis[2-(5-phenyloxazoly1)]benzene (POPOP)-toluene mixture (4 g PPO, $50 \mathrm{mg}$ POPOP/ liter of toluene) or in a Cab-O-Sil counting mixture $(772 \mathrm{ml}$ of xylene, $772 \mathrm{ml}$ of dioxane, $456 \mathrm{~m} 1$ of absolute alcohol, 10 $\mathrm{g}$ of PPO, $110 \mathrm{mg}$ of POPOP, $160 \mathrm{~g}$ of naphthalene, $80 \mathrm{~g}$ of Cab-O-Sil).

$\mathrm{CO}_{2}$ and $\mathrm{O}_{2}$ content of blood were measured manometrically by the technique of Van Slyke and Neil (20). ${ }^{14} \mathrm{CO}_{2}$ in blood was determined by a rotating microdiffusion technique (21). Immediately after withdrawal, $5.0 \mathrm{ml}$ of blood was mixed with $1.0 \mathrm{ml}$ of $2.5 \mathrm{~N} \mathrm{NaOH}$ to maintain the $\mathrm{CO}_{2}$ in a nongaseous phase. With this method, storage for as long as $48 \mathrm{hr}$ before analysis resulted in no significant loss of activity. For analysis, $2 \mathrm{ml}$ of this mixture was placed in a $30 \mathrm{ml}$ Wheaton specimen bottle. $2 \mathrm{ml}$ of $85 \%$ lactic acid was added and the bottle was immediately sealed by a stopper. ${ }^{14} \mathrm{CO}_{2}$ released during subsequent rotation of the bottle was absorbed by hyamine-saturated filter paper traps held by the bottle stopper. Radioactivity of the sample was determined using a methanol, toluene, PPO-POPOP counting mixture. Mean recovery of activity on 10 replicate samples of a standard $\mathrm{NaH}^{14} \mathrm{CO}_{3}$ solution was $98.3 \%$ by this technique. All determinations of radioactivity were corrected for quenching by calculation of counting efficiency utilizing the channels ratio technique. Activity was subsequently expressed as disintegrations per minute. Lactate was analyzed enzymatically by a modification of the technique of Horn and Bruns (22). Duplicate lactate determinations agreed within an average of 0.03 mmoles/liter. Glucose was determined by the ferricyanide technique on a Technicon AutoAnalyzer (23) with a coefficient of variation of $1.5 \%$. Acetoacetate (24), betahydroxybutyrate (24), and glycerol (25) were analyzed enzymatically. For acetoacetate and beta hydroxybutyrate the recovery of known amounts added to blood were $84.0 \pm 5.5 \%$ (SD) and $91.4 \pm 5.4 \%$, respectively. The coefficient of variation for the glycerol method was $3.0 \%$.

The fractional extractions of FFA, palmitate $-{ }^{14} \mathrm{C}$, and other metabolites were calculated on the basis of their arterial (a) and coronary sinus (cs) concentrations: fractional extraction $(E)=(a-c s) / a$. The myocardial uptake of FFA ( $\mu \mathrm{Eq} /$ liter) was computed as the product of $\mathrm{E}$ and the arterial plasma FFA concentration. The fractional oxidation of the FFA taken up was determined as the ratio ${ }^{14} \mathrm{CO}_{2}$ $(c s-a) / F F A-{ }^{14} \mathrm{C}(a-c s)$ after hematocrit correction. Oxygen consumption from FFA oxidation was calculated on the basis of 24.7 moles of oxygen consumed per mole of

TABLE II

Arterial (a) and Coronary Sinus (cs) Concentrations and Fractional Extraction of FFA and palmitate- ${ }^{14} C$ Specific Activity $(S A)$ and Fractional Oxidation of palmitate- ${ }^{14} C$

\begin{tabular}{|c|c|c|c|c|c|c|c|c|c|c|}
\hline \multirow[b]{3}{*}{ Subject } & \multicolumn{3}{|c|}{ Free fatty acids } & \multicolumn{3}{|c|}{ palmitate-14C } & \multicolumn{2}{|c|}{ SA palmitate-14C } & \multirow{3}{*}{$\begin{array}{l}{ }^{14} \mathrm{CO}_{2}, \\
\mathrm{cs}-\mathrm{a}\end{array}$} & \multirow{3}{*}{$\begin{array}{c}\text { Fraction } \\
\text { of palmi- } \\
\text { tate-14C } \\
\text { oxidized }\end{array}$} \\
\hline & \multirow[b]{2}{*}{ a } & \multirow[b]{2}{*}{ cs } & \multirow{2}{*}{$\begin{array}{l}\text { Fractional } \\
\text { extraction }\end{array}$} & \multirow[b]{2}{*}{$\mathbf{a}$} & \multirow[b]{2}{*}{ cs } & \multirow{2}{*}{$\begin{array}{l}\text { Fractional } \\
\text { extraction }\end{array}$} & & & & \\
\hline & & & & & & & a & cs & & \\
\hline & \multicolumn{2}{|c|}{$\begin{array}{c}\mu m o l e s / \text { liter* } \\
\text { plasma }\end{array}$} & $\%$ & \multicolumn{2}{|c|}{$d p m / m l^{*}$ plasma } & $\%$ & \multicolumn{2}{|c|}{$d p m / \mu E q$} & $\begin{array}{c}d p m / m l \\
\text { blood }\end{array}$ & $\%$ \\
\hline B. C. & 864 & 576 . & 33.3 & 2446 & 1276 & 47.8 & 11,330 & 9,310 & 306 & 48.2 \\
\hline J. G. & 718 & 543 & 24.4 & 2388 & 923 & 61.3 & 12,310 & 5,560 & 481 & 57.6 \\
\hline M. F. & 903 & 779 & 13.7 & 1609 & 1167 & 27.5 & 6,330 & 5,170 & 180 & 63.6 \\
\hline V. A. & 808 & 599 & 25.9 & 1601 & 972 & 39.4 & 9,470 & 6,570 & 181 & 49.3 \\
\hline J. H. & 792 & 679 & 14.3 & 2974 & 1934 & 35.0 & 13,810 & 10,570 & 272 & 41.8 \\
\hline J. T. & 539 & 349 & 35.3 & 1950 & 999 & 48.8 & 13,220 & 10,760 & 227 & 38.2 \\
\hline P. D. & 861 & 708 & 17.8 & 1418 & 757 & 46.6 & 6,680 & 4,020 & 156 & 40.2 \\
\hline W. T. & 677 & 523 & 22.7 & 2290 & 1060 & 53.7 & 11,240 & 7,690 & 414 & 62.7 \\
\hline A. $\mathrm{R}$. & 1441 & 998 & 30.7 & 2159 & 1247 & 42.2 & 4,940 & 4,070 & 281 & 57.1 \\
\hline J. M. & 1800 & 1301 & 27.7 & 3123 & 1927 & 38.3 & 6,580 & 5,580 & 321 & 43.2 \\
\hline E. C. & 1015 & 810 & 20.2 & 2353 & 1456 & 38.1 & - & - & 323 & 56.8 \\
\hline G. M. & 500 & 439 & 12.2 & 959 & 445 & 54.1 & - & - & 234 & 82.7 \\
\hline Mean & 910 & 692 & 23.2 & 2107 & 1180 & 44.4 & 9,590 & 6,930 & 281 & 53.5 \\
\hline SD & 371 & 260 & 7.8 & 631 & 436 & 9.5 & 3,230 & 2,530 & 97 & 12.7 \\
\hline T. F. $\S$ & 1154 & 1049 & 9.1 & 5396 & 4163 & 22.9 & 17,460 & 14,920 & 432 & 62.6 \\
\hline
\end{tabular}

* Based on 3 to 5 observations for each subject.

¥ Specific activity (SA) based on data in Table III, assuming 16:0,16:1, 18:0,18:1, and 18:2 to be 85\% of total FFA. $\$$ Subject T. F. included separately, owing to documented myocardial ischemia during the study. 

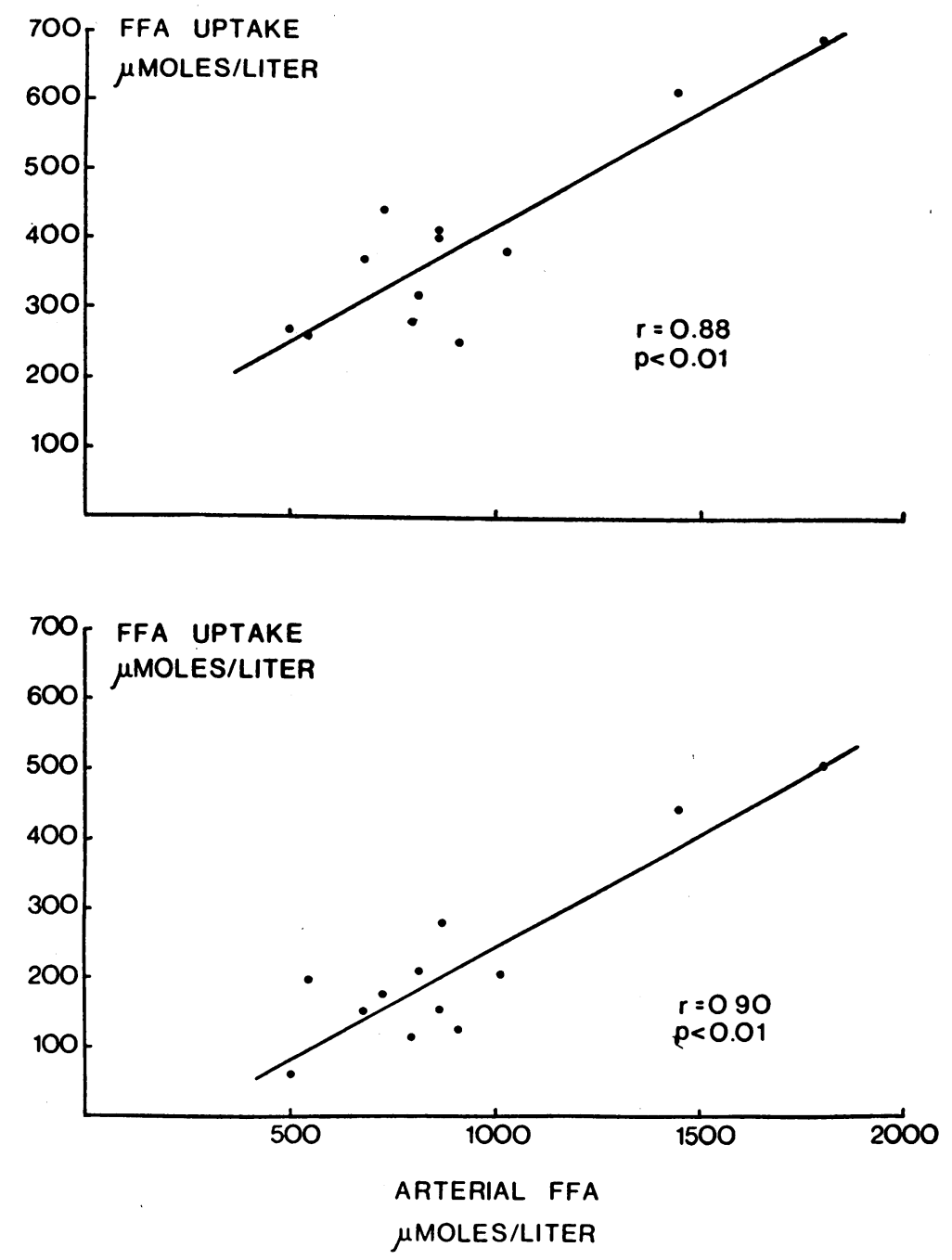

Figure 1 Correlations between FFA uptake and the arterial FFA concentration. Upper graph based on FFA ${ }^{14} \mathrm{C}$ fractional extraction (dpm uptake converted to $\mu$ moles/liter uptake). Lower graph based on $(a-c s)$ FFA.

FFA. Statistical calculations were performed according to Snedecor (26), and all data presented in the text are in the form $($ mean $\pm \mathrm{SD})$.

\section{RESULTS}

Steady arterial and coronary sinus levels of FFA were observed throughout the study in all subjects, except J. M. who showed a gradual increase in FFA concentration over $60 \mathrm{~min}$. A possible cause of the elevation in J. M. was progressive antecubital discomfort at the site of catheter insertion. During the last 15 min of his study an increase in arterial FFA of approximately $10 \%$ occurred. The mean fractional extraction of FFA for the group (Table II) was $23.2 \pm 7.8 \%$ (mean $\pm \mathrm{SD}$ ). With increasing arterial levels of FFA, (a-cs) concentration differences rose $(P<0.01$, Fig. 1$)$.

Analysis of individual plasma FFA by gas-liquid chromatography is given in Table III. The palmitate fraction of FFA (per cent of the sum of palmitate, palmitoleate, stearate, oleate, and linoleate) did not differ significantly in arterial and coronary sinus samples. The same finding was true for the other FFA analyzed in this manner.

A steady state for arterial and coronary sinus concentration of $\mathrm{FFA}-{ }^{14} \mathrm{C}$ was generally achieved within 15-20 min after initiation of the infusion and was maintained until the infusion was terminated. The rapid fall in $\mathrm{FFA}-{ }^{\mathrm{I}} \mathrm{C}$ concentration within $5 \mathrm{~min}$ of termination 
TABLE III

Relative Arterial (a) and Coronary Sinus (cs) Concentrations of Individual FFA Measured by Gas-Liquid Chromatography*

\begin{tabular}{|c|c|c|c|c|c|c|c|c|c|c|}
\hline \multirow[b]{2}{*}{ Subject } & \multicolumn{2}{|c|}{$16: 0$} & \multicolumn{2}{|c|}{$16: 1$} & \multicolumn{2}{|c|}{$18: 0$} & \multicolumn{2}{|c|}{$18: 1$} & \multicolumn{2}{|c|}{$18: 2$} \\
\hline & a & cs & a & cs & a & cs & a & cs & a & cs \\
\hline B. C. & 29.4 & 28.0 & 4.1 & 5.2 & 10.9 & 9.4 & 41.1 & 44.5 & 14.5 & 12.9 \\
\hline J. G. & 31.8 & 36.0 & 4.2 & 3.7 & 17.7 & 16.4 & 24.0 & 25.8 & 22.3 & 18.2 \\
\hline M. F. & 33.1 & 34.1 & 4.3 & 3.9 & 13.9 & 14.4 & 29.1 & 27.9 & 19.6 & 19.6 \\
\hline V.A. & 24.6 & 29.1 & 6.3 & 4.8 & 8.2 & 8.6 & 40.7 & 33.4 & 20.1 & 24.0 \\
\hline J. H. & 32.0 & 31.7 & 2.6 & 4.0 & 13.3 & 12.1 & 35.7 & 29.4 & 16.5 & 22.8 \\
\hline P. D. & 29.0 & 31.3 & 1.4 & 3.7 & 11.1 & 11.5 & 41.6 & 32.5 & 17.0 & 21.0 \\
\hline J. T. & 32.2 & 31.3 & 2.7 & 3.0 & 15.1 & 16.2 & 31.8 & 29.2 & 18.2 & 20.4 \\
\hline W. T. & 35.4 & 31.0 & 2.2 & 2.6 & 16.4 & 16.7 & 27.4 & 26.9 & 18.7 & 22.8 \\
\hline A. R. & 35.7 & 36.1 & 4.0 & 3.9 & 11.2 & 11.3 & 29.3 & 29.1 & 19.9 & 19.7 \\
\hline J. M. & 31.0 & 31.2 & 4.6 & 3.7 & 7.1 & 7.8 & 40.9 & 43.1 & 16.4 & 14.2 \\
\hline Mean & 31.4 & 32.0 & 3.6 & 3.9 & 12.5 & 12.4 & 34.2 & 32.2 & 18.3 & 19.6 \\
\hline SD & 3.2 & 2.7 & 1.4 & 0.8 & 3.4 & 3.3 & 6.6 & 6.5 & 2.3 & 3.6 \\
\hline T. F. $\ddagger$ & 31.5 & 31.3 & 2.9 & 3.3 & 13.9 & 13.5 & 28.6 & 30.1 & 23.2 & 22.0 \\
\hline
\end{tabular}

* Percentages by weight of sum of the methyl esters of 16:0 (palmitic acid), 16:1 (palmitoleic acid), 18:0 (stearic acid), 18:1 (oleic acid), and 18:2 (linoleic acid).

$\ddagger$ Subject T. F. included separately owing to documented myocardial ischemia.

of infusion restricted metabolic radiopalmitate observations to the plateau state achieved during the infusion. The mean value for fractional extraction of $\mathrm{FFA}-{ }^{14} \mathrm{C}$ was $44.4 \pm 9.5 \%$ which is significantly higher $(P<$

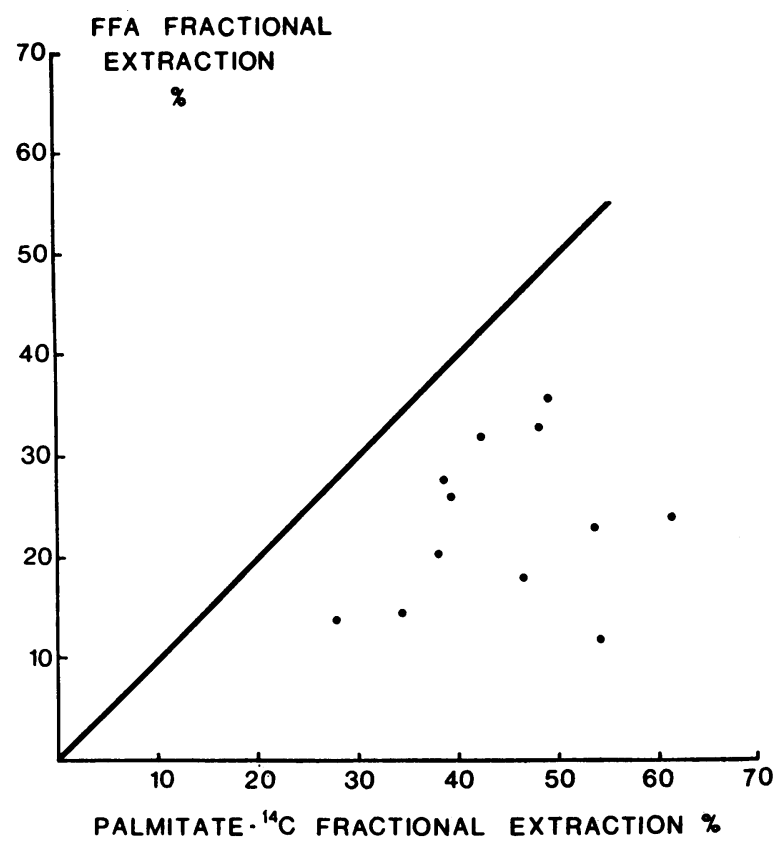

FIGURE 2 Correlation of fractional extraction of FFA with fractional extraction $F F A-{ }^{14} \mathrm{C}$. Solid line indicates a line of identity. A significant correlation between the two was not achieved.
0.001) than the corresponding value for unlabeled FFA. In addition, in every instance, the fractional extraction of FFA- ${ }^{14} \mathrm{C}$ exceeded that of unlabeled FFA (Fig. 2). This difference was in excess of $10 \%$ in every subject (Table II). Although the FFA- ${ }^{14} \mathrm{C}$ fractional extraction tended towards lower values with increasing arterial FFA concentration (Fig. 3), this was not statistically significant. The FFA uptake, based on FFA- ${ }^{14} \mathrm{C}$ extraction, was directly related to the arterial FFA concentration $(P<0.01$, Fig. 1$)$. In the five subjects in whom coronary blood flow was measured the mean myocardial consumption of FFA, based on FFA- ${ }^{14} \mathrm{C}$ extraction and calculated from data in Tables I and II, was $13.8 \pm 2.9$ $\mu$ moles $/ 100 \mathrm{~g}$ per min, of which $7.6 \pm 2.3 \mu$ moles $/ 100 \mathrm{~g}$ per min were oxidized.

The mean arterial concentration of triglycerides (TG) was $1.23 \pm 0.46 \mathrm{mmoles} / \mathrm{liter}$ of plasma. The coronary sinus TG concentration was $1.12 \pm 0.45$ mmoles/ liter $(\mathrm{n}=11)$. The $\mathrm{a}-\mathrm{cs}$ difference was significant $(P<0.05)$. The mean fractional extraction was $9.7 \pm$ $15.0 \%$. These values are based on two to six pairs of observations for each individual. In six subjects there was a measurable incorporation of $\mathrm{FFA}-{ }^{14} \mathrm{C}$ into TG ( $>200 \mathrm{dpm} / \mathrm{ml}$ of $\mathrm{TG}{ }^{-14} \mathrm{C}$ ). The arterial and coronary sinus TG radioactivity levels were $376 \pm 70 \mathrm{dpm} / \mathrm{ml}$ and $306 \pm 57 \mathrm{dpm} / \mathrm{ml}(P<0.025)$. In every instance, the coronary sinus level was lower than the corresponding arterial concentration. The mean fractional extraction was $17.9 \pm 12.0 \%$.

${ }^{14} \mathrm{CO}_{2}$ production by the heart tended to level off after $20 \mathrm{~min}$ of infusion (Fig. 4). With shorter infusion times, 


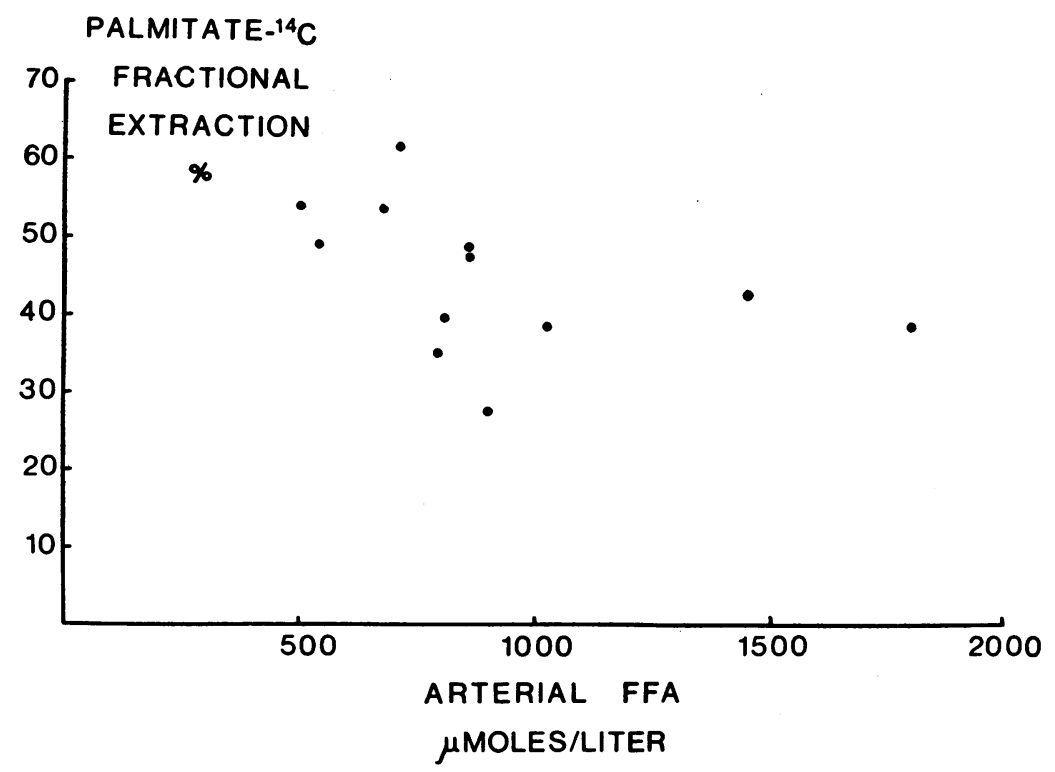

FIgURE 3 Correlation of FFA- ${ }^{14} \mathrm{C}$ fractional extraction with the arterial FFA concentration. A significant correlation between the two was not achieved.

steady-state ${ }^{14} \mathrm{CO}_{2}$ production was not fully achieved and consequently led to an underestimation of the fractional oxidation of $\mathrm{FFA}-{ }^{14} \mathrm{C}$. In these instances the three (cs $-\mathrm{a}){ }^{14} \mathrm{CO}_{2}$ differences best approximating a plateau were used. The mean value for fractional oxidation given in Table II $(53.5 \pm 12.7 \%)$ is therefore likely to slightly underestimate the true oxidation. It is further noted that even with the more prolonged infusions (cs - a) ${ }^{14} \mathrm{CO}_{2}$ differences in several subjects had still not reached a plateau. Calculations of their data were made as described above for the shorter infusion periods.

FFA, palmitic acid- ${ }^{14} \mathrm{C}$, and ${ }^{14} \mathrm{CO}_{2}$ data for an illustrative subject (B. C.) are seen in Fig. 5. The steadily rising arterial ${ }^{14} \mathrm{CO}_{2}$ level is noted in addition to the relatively steady-state FFA and palmitic acid- ${ }^{14} \mathrm{C}$ levels.

After termination of the infusion, ${ }^{14} \mathrm{CO}_{2}$ production continued for variable periods. In several subjects, measurable levels were monitored for as long as $15 \mathrm{~min}$

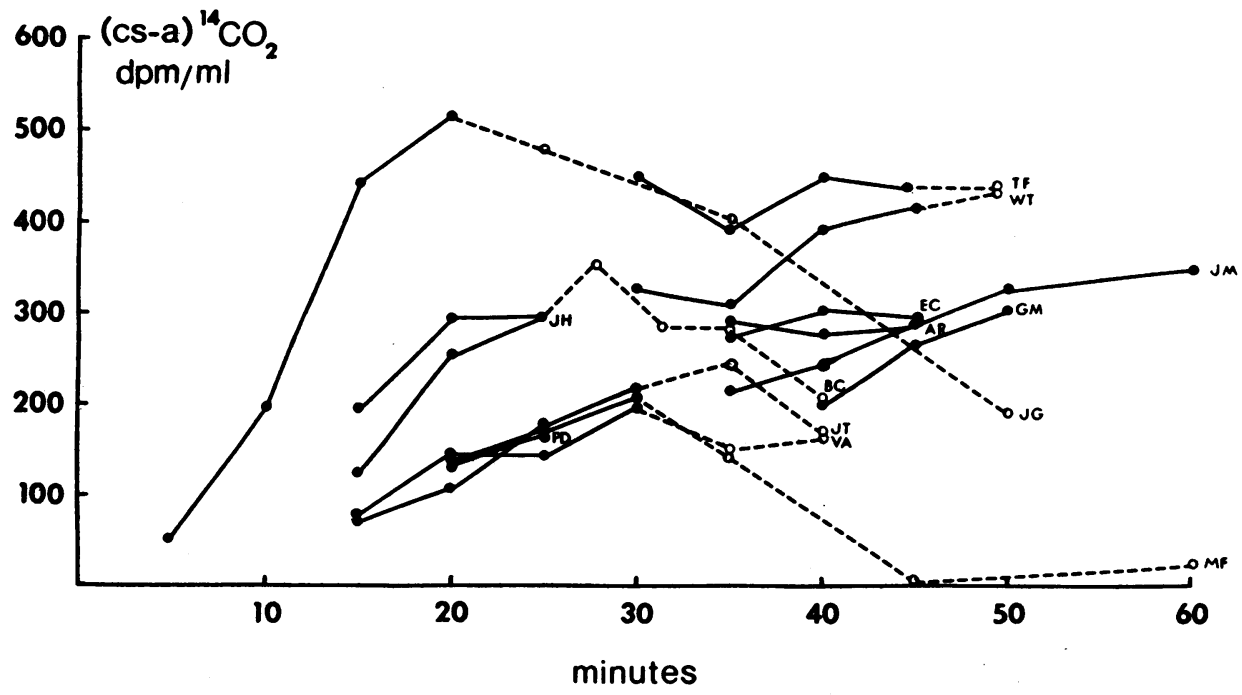

FIGURE $4{ }^{14} \mathrm{CO}_{2}$ production by the heart during (solid lines) and after (broken lines) infusion of palmitate ${ }^{-14} \mathrm{C}$. 


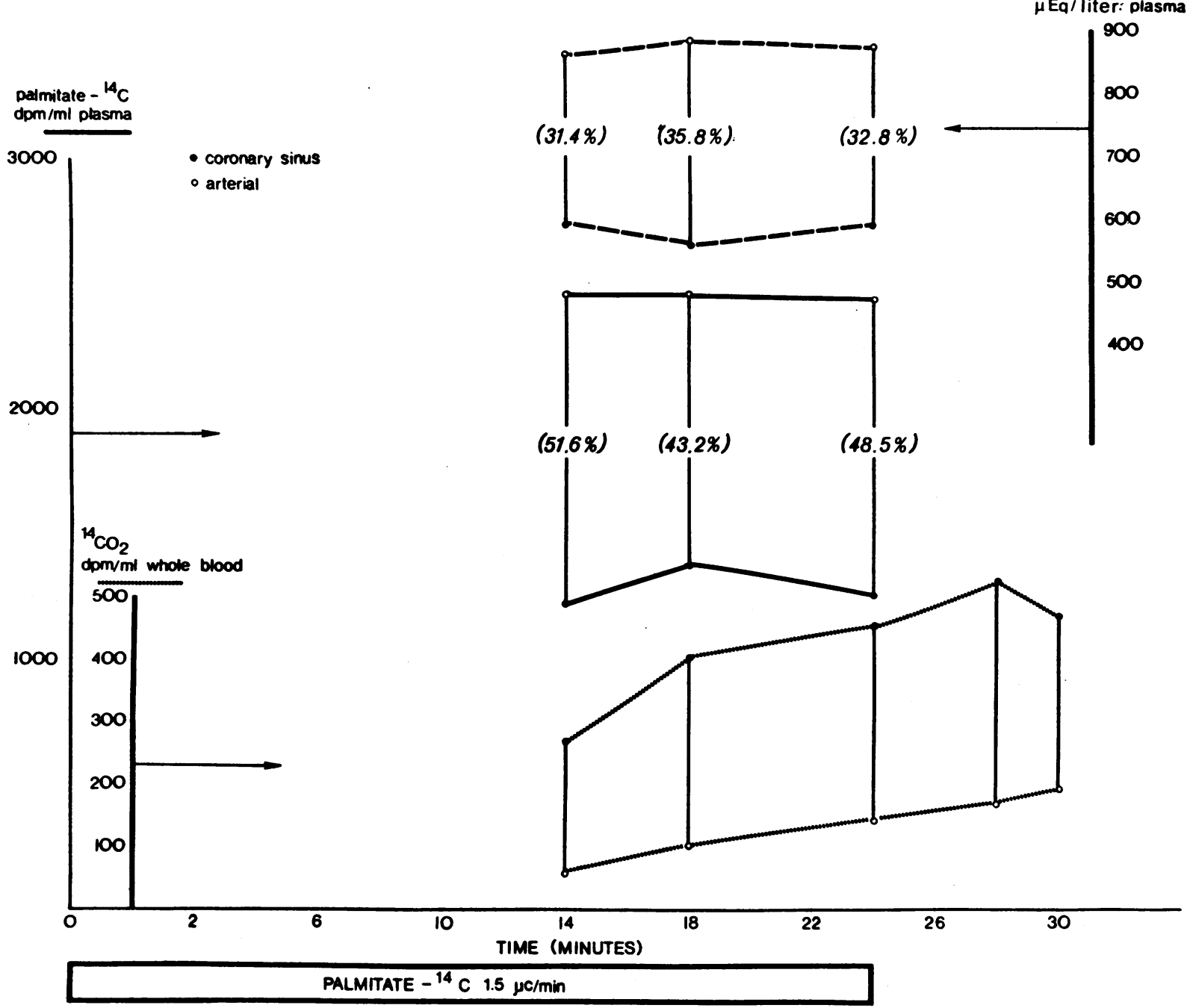

FIGURe 5 Data from an individual experiment (subject B. C.) during and after a palmitic acid- ${ }^{14} \mathrm{C}$ infusion at $1.5 \mu \mathrm{c} / \mathrm{min}$. Percentages in parentheses are the fractional extractions for FFA $-{ }^{14} \mathrm{C}$ and FFA.

(Fig. 4). The 5 min postinfusion (cs - a) ${ }^{14} \mathrm{CO}_{2}$ level was often comparable to the last value noted during the infusion. For some subjects, this value was incorporated into the calculation of fractional oxidation when it provided the best third value for approximating the (cs a) ${ }^{14} \mathrm{CO}_{2}$ plateau. It is recognized, however, that an even higher $(\mathrm{cs}-\mathrm{a}){ }^{14} \mathrm{CO}_{2}$ value may have been reached between the end of the infusion and the 5 min postinfusion measurement in those subjects whose $(\mathrm{cs}-\mathrm{a}){ }^{14} \mathrm{CO}_{2}$ curve was still rising at the end of the infusion period.

Small amounts of radioactivity were found in the perchloric acid extracts of blood. At the end of the FFA ${ }^{14} \mathrm{C}$ infusion period the mean arterial radioactivity level was $192 \pm 50 \mathrm{dpm} / \mathrm{ml}$ and the mean coronary sinus level $174 \pm 37 \mathrm{dpm} / \mathrm{ml}(\mathrm{n}=9)$. This difference is not significant.

The observed cardiac oxygen uptake and extractions of the major nonlipid substrates are presented in Table IV. The fractional extraction of oxygen showed relatively small variation $(73.1 \pm 4.6 \%)$. The oxygen equivalence of the sum of measured nonlipid substrates, calculated on the assumption of complete oxidation, was 30.0 $\pm 17.3 \%$ of the $(\mathrm{a}-\mathrm{cs})$ oxygen difference. The corresponding values for individual substrates are $13.1 \pm$ $15.4 \%$ for glucose, $8.6 \pm 5.8 \%$ for lactate, $4.2 \pm 3.6 \%$ for $\beta$-hydroxybutyrate, and $2.5 \pm 2.8 \%$ for acetoacetate. No significant $(a-c s)$ concentration difference was observed for glycerol. 
TABLE IV

Oxygen Uptake and Nonlifid Substrate Utilization

\begin{tabular}{|c|c|c|c|c|c|c|c|c|c|c|c|c|c|}
\hline \multirow[b]{2}{*}{ Subject } & \multicolumn{2}{|c|}{ Oxygen } & \multirow{2}{*}{$\begin{array}{l}\text { Fractional } \\
\text { extraction }\end{array}$} & \multicolumn{2}{|c|}{ Lactate } & \multicolumn{2}{|c|}{ Glucose } & \multicolumn{2}{|c|}{$\begin{array}{c}\beta \text {-hydroxy- } \\
\text { butyrate }\end{array}$} & \multicolumn{2}{|c|}{ Acetoacetate } & \multicolumn{2}{|c|}{ Glycerol } \\
\hline & a & $a-c s$ & & a & $a-c s$ & a & $a-c s$ & $\mathbf{a}$ & $a-c s$ & a & $a-c s$ & a & $a-c s$ \\
\hline & \multicolumn{2}{|c|}{ mmoles/liter } & $\%$ & \multicolumn{2}{|c|}{ mmoles/liter } & \multicolumn{2}{|c|}{ mmoles/liter } & \multicolumn{2}{|c|}{ mmoles/liter } & \multicolumn{2}{|c|}{ mmoles/liter } & \multicolumn{2}{|c|}{ mmoles/liter } \\
\hline B. C. & 8.25 & 6.35 & 77.0 & 0.32 & 0.09 & 5.04 & 0.02 & - & - & - & - & - & - \\
\hline J. G. & 8.12 & 5.71 & 70.3 & 0.35 & 0.16 & 4.09 & 0.12 & - & - & - & - & - & - \\
\hline M. F. & 6.10 & 4.10 & 67.2 & 0.44 & 0.14 & 3.72 & 0.04 & 0.190 & 0.090 & 0.150 & 0.090 & 0.060 & -0.002 \\
\hline V. A. & 6.86 & 5.14 & 74.9 & 0.44 & 0.08 & 4.16 & 0.07 & 0.120 & 0.041 & 0.040 & 0.000 & 0.046 & 0.016 \\
\hline J. H. & 6.67 & 5.01 & 75.1 & 0.45 & 0.11 & 5.44 & 0.18 & 0.086 & 0.037 & 0.030 & 0.005 & 0.034 & -0.033 \\
\hline J. T. & 6.02 & 4.66 & 77.4 & 0.61 & 0.32 & 5.28 & 0.36 & 0.021 & 0.004 & 0.040 & 0.015 & 0.036 & 0.010 \\
\hline P. D. & 7.78 & 5.03 & 64.7 & 0.42 & 0.05 & 4.33 & 0.03 & 0.243 & 0.115 & 0.125 & 0.065 & 0.035 & -0.009 \\
\hline W. T. & 7.95 & 5.58 & 70.2 & 0.54 & 0.16 & 3.89 & 0.00 & 0.040 & 0.017 & 0.050 & 0.020 & 0.085 & -0.007 \\
\hline A. $\mathbf{R}$. & 8.66 & 6.97 & 80.5 & 0.52 & 0.10 & 6.10 & 0.00 & 0.272 & 0.104 & 0.120 & 0.080 & 0.135 & 0.023 \\
\hline J. M. & 7.62 & 5.37 & 70.5 & 0.52 & 0.12 & 5.20 & 0.11 & 0.122 & 0.046 & 0.060 & 0.020 & 0.179 & -0.118 \\
\hline E. C. & 7.62 & 5.82 & 76.4 & 0.63 & 0.12 & 4.52 & 0.39 & 0.060 & 0.020 & 0.068 & 0.008 & 0.042 & 0.025 \\
\hline G. M. & 8.19 & 5.97 & 72.9 & 0.97 & 0.39 & 5.82 & 0.05 & 0.036 & 0.011 & 0.060 & 0.020 & 0.045 & -0.008 \\
\hline Mean & 7.49 & 5.48 & 73.1 & 0.52 & 0.15 & 4.72 & 0.11 & 0.119 & 0.049 & 0.074 & 0.032 & 0.070 & -0.025 \\
\hline SD & 0.87 & 0.77 & 4.6 & 0.17 & 0.10 & 0.76 & 0.11 & 0.089 & 0.040 & 0.042 & 0.033 & 0.050 & 0.042 \\
\hline T. F.* & 7.75 & 5.75 & 74.2 & 0.45 & -0.08 & 5.38 & 0.38 & 0.280 & 0.070 & 0.210 & $\theta .150$ & 0.131 & 0.008 \\
\hline
\end{tabular}

* Subject T. F. included separately owing to documented myocardial ischemia during the study.

The measured myocardial oxidation of FFA, based on sponding value based on the (a - cs) concentration difthe FFA- ${ }^{14} \mathrm{C}$ extraction and the observed fractional oxidation was calculated to consume $53.2 \pm 14.4 \%$ of the $(\mathrm{a}-\mathrm{cs})$ oxygen difference (Table V). The corre-

ference for unlabeled FFA and assuming $100 \%$ oxidation was $57.2 \pm 32.0 \%$. When these values were combined with the oxygen equivalents of nonlipid substrates

TABLE V

Individual and Combined Contributions to Cardiac Oxygen Consumption of FFA and Nonlipid Substrates

\begin{tabular}{|c|c|c|c|c|c|c|c|c|c|c|c|}
\hline \multirow[b]{4}{*}{ Subject } & \multicolumn{2}{|c|}{ FFA uptake } & \multirow{4}{*}{$\begin{array}{l}\text { FFA }(2)^{*} \\
\text { oxidized } \\
\text { based on } \\
{ }^{14} \mathrm{CO}_{2} \\
\text { produc- } \\
\text { tion } \\
(3)\end{array}$} & \multicolumn{6}{|c|}{ Oxygen equivalents } & \multirow{2}{*}{\multicolumn{2}{|c|}{$\begin{array}{l}\text { Percentage of total } \\
\text { oxygen consumed }\end{array}$}} \\
\hline & \multirow{3}{*}{$\begin{array}{c}\text { Based on } \\
(\mathrm{a}-\mathrm{cs}) \\
\text { FFA } \\
(1)\end{array}$} & \multirow{3}{*}{$\begin{array}{l}\text { Based on } \\
\text { FFA- } \\
\text { 14C ex- } \\
\text { traction } \\
\text { (2) }\end{array}$} & & \multirow{2}{*}{\multicolumn{2}{|c|}{ FFA (3)* }} & \multirow{2}{*}{\multicolumn{2}{|c|}{$\begin{array}{l}\text { FFA (1)* as- } \\
\text { suming com- } \\
\text { lete oxidation }\end{array}$}} & \multirow{2}{*}{\multicolumn{2}{|c|}{$\begin{array}{l}\text { Nonlipid } \\
\text { substrates }\end{array}$}} & & \\
\hline & & & & & & & & & & & \\
\hline & & & & $(4)$ & & $(5$ & & ( & & $(6) *$ & $(6) *$ \\
\hline & $\begin{array}{c}\text { Mmoles/ } \\
\text { liter }\end{array}$ & 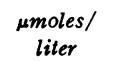 & $\begin{array}{c}\text { rmoles / } \\
\text { liter }\end{array}$ & $\begin{array}{c}\text { mmoles } / \\
\text { liter }\end{array}$ & $\% \ddagger$ & $\begin{array}{l}\text { mmoles/ } \\
\text { liter }\end{array}$ & $\% \ddagger$ & $\begin{array}{c}\text { mmoles/ } \\
\text { liter }\end{array}$ & $\% \ddagger$ & & \\
\hline B. C. & 1568 & 224 & 108 & 2.67 & 42.0 & 3.85 & 60.7 & $0.39 \|$ & $6.1 \|$ & $48.1 \|$ & $66.8 \|$ \\
\hline J. G. & 100 & 251 & 145 & 3.57 & 62.5 & 2.47 & 43.2 & $1.20 \|$ & $21.0 \|$ & $83.5 \|$ & $64.2 \|$ \\
\hline M. F. & 79 & 159 & 101 & 2.50 & 60.9 & 1.96 & 47.7 & 1.43 & 34.8 & 95.7 & 82.5 \\
\hline V. A. & 122 & 185 & 91 & 2.26 & 43.9 & 3.02 & 58.7 & 0.84 & 16.4 & 60.3 & 75.1 \\
\hline J. H. & 71 & 174 & 73 & 1.79 & 35.8 & 1.75 & 35.0 & 1.60 & 31.9 & 67.7 & 66.9 \\
\hline J. T. & 120 & 166 & 63 & 1.56 & 33.6 & 2.96 & 63.5 & 3.20 & 68.6 & 102.2 & 132.1 \\
\hline P. D. & 90 & 236 & 95 & 2.34 & 46.5 & 2.22 & 44.2 & 1.11 & 22.0 & 68.5 & 66.2 \\
\hline W. T. & 83 & 195 & 122 & 3.02 & 54.2 & 2.04 & 36.5 & 0.64 & 11.4 & 65.6 & 47.9 \\
\hline A. $\mathbf{R}$. & 238 & 321 & 187 & 4.62 & 66.3 & 5.89 & 84.5 & 1.09 & 15.6 & 81.9 & 100.1 \\
\hline J. M. & 310 & 429 & 185 & 4.58 & 85.2 & 7.66 & 142.6 & 1.31 & 24.3 & 109.5 & 166.9 \\
\hline E. C. & 132 & 249 & 141 & 3.49 & 59.9 & 3.26 & 56.0 & 2.82 & 48.5 & 108.4 & 104.5 \\
\hline G. M. & 34 & 151 & 125 & 3.08 & 51.7 & 0.84 & 14.1 & 1.60 & 26.8 & 82.5 & 40.9 \\
\hline Mean & 128 & 228 & 120 & 2.96 & 53.2 & 3.16 & 57.2 & 1.56 & 30.0 ป & 84.2 व & $88.3 \pi$ \\
\hline SD & 77 & 80 & 40 & 0.98 & 14.4 & 1.90 & 32.0 & 0.83 & 17.3 & 18.6 & 38.8 \\
\hline T. F.** & 59 & 148 & 93 & 2.29 & 39.8 & 1.45 & 25.3 & 3.20 & 55.6 & 95.4 & 80.9 \\
\hline
\end{tabular}

* Refers to column number.

$\ddagger$ Percentage of $(\mathrm{a}-\mathrm{cs})$ oxygen.

\& All concentrations given are for whole blood.

|| Does not include $\beta$-hydroxybutyrate and acetoacetate.

I Does not include subjects B. C. and J. G.

** Subject T. F. included separately owing to documented myocardial ischemia during the study. 
$84.2 \pm 18.6 \%$ and $88.3 \pm 38.8 \%$, respectively, of oxygen consumption could be accounted for.

The mean cardiac respiratory quotient ( $R Q)$ was $0.62 \pm 0.08$. Other than as a gross indication of the predominant lipid oxidation further reference will not be made to $R Q$ values.

\section{DISCUSSION}

In spite of considerable clinical heterogeneity in the present study group, all subjects (with the exception of T. F.) showed significant myocardial lactate extraction indicating adequate myocardial oxygenation (27, 28). The results from T. F.'s study are discussed separately and were not included in the calculated mean values. Other factors to be considered include the administration of a digitalis preparation (J. T., J. H., A. R., and J. M.) and the presence of clinical diabetes mellitus in two subjects (T. F. and A. R.). Although the acute administration of ouabain has been shown to increase the fractional oxidation of $\mathrm{FFA}-{ }^{14} \mathrm{C}$ in the perfused rabbit heart (29), there is no evidence of a comparable influence of digitalis preparations during chronic administration in the intact human heart. For this reason and owing to the extreme mildness of subject A. R.'s diabetes and the absence of information regarding correlation of myocardial metabolism with results of the intravenous glucose tolerance test, all subjects, exclusive of $\mathrm{T}$. F., were considered as a single group.

Quantitative calculations of myocardial FFA metabolism were complicated by the finding in all subjects of a lower specific activity for FFA in coronary sinus blood than in arterial. This observation parallels that of Evans, Opie, and Shipp (30) for the isolated perfused rat heart. The same observation can also be expressed as a higher fractional extraction of $\mathrm{FFA}-{ }^{14} \mathrm{C}$ than of unlabeled FFA (Table II). The latter value in the present study agrees closely with the corresponding data for other and larger study groups $(5,7,8,10,31)$. This disparity in chemical and labeled FFA fractional extraction could be ascribed to several mechanisms: (a) release of unlabeled FFA from tissue lipid stores into coronary sinus blood; (b) hydrolysis of circulating triglycerides by lipoprotein lipase and release of unlabeled FFA into cs blood; $(c)$ the nature of the exogenously prepared FFA- ${ }^{14} \mathrm{C}$-albumin complex may have led to preferential extraction of FFA- ${ }^{14} \mathrm{C}$; and $(d)$ true myocardial preferential extraction of circulating palmitate.

The human heart is not without potential sources for a release of FFA to coronary sinus blood. In the subepicardial tissue, particularly in the atrioventricular and interventricular grooves, there is a considerable amount of fat and the fat may extend in strips over the entire surface of the heart (32). There have been no published descriptions of the venous drainage of this adipose tis- sue but it is not unreasonable to assume that it is being drained, at least in part, by the coronary sinus. Infiltration of the myocardium with fat has also been reported and in some cases in sufficient quantity to interfere with atrioventricular conduction (33). Moreover, intracellular lipid droplets have been demonstrated in myocardial cells : they appear to be formed by FFA esterification in the sarcoplasmic reticulum (34). Mobilization of FFA from any or all of these fat depots in the heart may possibly have contributed to a lower specific activity of FFA- ${ }^{14} \mathrm{C}$ in cardiac venous blood. It is noted that the human heart differs from most animal species in that it possesses a considerably greater quantity of subepicardial adipose tissue.

Hydrolysis of plasma triglycerides may also contribute to a relative increase in unlabeled FFA in coronary sinus blood. This possibility receives support from work in the perfused rat heart (35) showing an increase in FFA in the perfusate during perfusion with low density lipoproteins $(\mathrm{d}<1.006)$. That the human heart has the capacity to hydrolyze circulating triglycerides is strongly suggested by the recent demonstration in vivo of the presence of heparin-releasable lipoprotein lipase from the human heart (36). This finding has been confirmed in this laboratory in two subjects. In the present study the arterial triglyceride concentration was significantly greater than the coronary sinus concentration. This was true for both the chemical and radioactive determination of triglycerides. This finding is supported by other work $(37,38)$ but not by all studies $(3,7,8)$. The data for labeled triglycerides do not depend on glycerol determinations as do the analyses of unlabeled triglycerides, and they are for this reason probably more reliable in studies of the release of esterbound fatty acids.

The fate of the fatty acids released through hydrolysis of circulating triglycerides has not been determined. Assuming complete hydrolysis of the $(\mathrm{a}-\mathrm{cs})$ triglyceride difference and myocardial uptake of all released FFA, the resulting mean oxygen equivalents would be $2.5 \mathrm{mmoles} /$ liter of blood. This is based on only $50 \%$ fractional oxidation and is far in excess of available oxygen equivalents after accounting for proven oxidation of FFA and for other substrates shown to be extracted. This observation may support the hypothesis of release of fatty acids to coronary sinus blood from triglyceride hydrolysis. This possibility is not excluded by the absence of a significant $(a-c s$ ) concentration difference for glycerol, since glycerokinase is present in myocardium (39) and glycerol oxidation, presumably, can take place in the heart as has been shown to be the case for skeletal muscle (13). It should be noted that the occurrence of a release of unlabeled FFA to coronary sinus blood derived either from lipid stores in the 
heart or from hydrolysis of circulating triglycerides would invalidate the $(a-c s)$ concentration difference of unlabeled FFA as a measure of myocardial FFA uptake.

The use of an exogenously prepared FFA-albumin complex necessitates the assumption of identical handling of this complex and that produced endogenously. Although generally accepted, absolute evidence of identical metabolism has not been demonstrated. One must consider the possibility that preferential extraction of the exogenous labeled palmitate might occur and account for lower specific activity in coronary sinus samples. The possibility has been raised, based on isolated heart perfusion studies, that added radiopalmitate could be denied tight binding sites on albumin and thus be preferentially extracted (30). The methodology employed in our study was designed to avoid this possibility. Unlike studies using isolated perfused hearts, the exogenously prepared palmitate- ${ }^{14} \mathrm{C}$-albumin complex was infused peripherally into a large pool of endogenous FFA-albumin complexes. The electrostatic nature of the FFAalbumin bond $(40,41)$ makes it probable that endogenous and exogenous complexes rapidly interact and equilibrate, minimizing differences between exogenous and endogenous FFA-albumin complexes.

Previous studies of myocardial uptake of individual FFA $(7,10)$ reported slight preferential extraction of oleate and a relatively low degree of extraction of palmitate. We were unable to confirm these findings and could not demonstrate a significant difference in the palmitate fraction of total FFA found in arterial and coronary sinus blood. Our data indicate that net cardiac palmitate exchange correctly reflected net cardiac FFA exchange and preferential extraction of palmitate thus was not the explanation of the lower specific activity of FFA in coronary sinus blood. It should be noted, however, that if the $(a-c s)$ concentration difference represents a net value, (combining cardiac release and uptake of FFA) the question of selectivity with regard to the extraction of individual FFA cannot be determined unless studied with several different labeled FFA. One cannot assume from the data obtained in this study that palmitate and total FFA fractional extractions are identical, but data from animal studies $(42,43)$ and for exercising human skeletal muscle $(13,44)$ indicate that this approach may lead to only small errors.

The fractional contribution of FFA as a substrate in total myocardial metabolism, determined in the present study on the basis of $\mathrm{FFA}-{ }^{14} \mathrm{C}$ extraction and oxidation is in excellent agreement with previous reports derived by somewhat different techniques $(7,45)$. The quantitative importance of the high fractional extraction of FFA $-{ }^{14} \mathrm{C}$ is partly offset by the incomplete oxidation of FFA $-{ }^{14} \mathrm{C}$ resulting in an approximately equal estimate of FFA oxidation from these data and from (a-cs) concentration difference of unlabeled FFA, assuming $100 \%$ oxidation. The finding in this study of less than total oxidation of extracted FFA is in close agreement with results from animal studies $(30,43)$ and suggests that metabolic calculations should not be based on the assumption of immediate and total oxidation of all extracted substrate. Approximately $85 \%$ of the oxygen consumption can be accounted for if the $\mathrm{FFA}-{ }^{14} \mathrm{C}$ data are combined with the measured extraction of glucose, lactate, $\beta$-hydroxybutyrate, and acetoacetate. It has been assumed that these nonlipid substrates are being fully oxidized, but this may not necessarily be the case, as noted above and discussed earlier by Goodale, Olson, and Hackel (9), and in view of the finding of release of alanine to coronary sinus blood in normal subjects (3) and in patients with diabetes mellitus (46).

Several factors may contribute to the deficit in accounting for the total oxygen uptake. At the termination of the infusion period, ${ }^{14} \mathrm{CO}_{2}$ production had not reached an entirely steady-state level (Fig. 4). This finding might lead to a slight underestimation of FFA oxidation. Failure to achieve a ${ }^{14} \mathrm{CO}_{2}$ plateau could be attributed to two major factors: $(a)$ shorter $(<30 \mathrm{~min})$ infusions failed to substantially label all the rapidly turning over substrate pools in the heart, and $(b)$ longer infusions resulted in increasing levels of labeled triglyceride, $\beta$-hydroxybutyrate, and acetoacetate, all of which could contribute to increasing amounts of ${ }^{14} \mathrm{CO}_{2}$ production. With regard to the latter two substrates, the continuing rise in ${ }^{14} \mathrm{CO}_{2}$ would not suggest an underestimation of FFA oxidation but could in theory result in an overestimate. Measurement of both unlabeled and labeled triglycerides indicates that these neutral lipids may be hydrolyzed during passage across the coronary bed. Oxidation of FFA thus released may well account for a portion of the residual oxygen uptake, and may possibly contribute to the ${ }^{14} \mathrm{CO}_{2}$ production.

A small net cardiac extraction of labeled water-soluble compounds was observed and probably reflects uptake of labeled $\beta$-hydroxybutyrate and acetoacetate formed in the liver during the infusion. The possibility of a simultaneous release by the myocardium of labeled water soluble compounds making up part of the FFA- ${ }^{14} \mathrm{C}$ uptake not accounted for by ${ }^{14} \mathrm{CO}_{2}$ production, as seen in exercising skeletal muscle (13), cannot be excluded. The considerably lower fractional extraction of the labeled water soluble components $(8.0 \pm 8.3 \%)$, when compared to the combined extractions for $\beta$-hydroxybutyrate and acetoacetate, does suggest the possibility of release of ketones by the heart into the coronary sinus.

The limited number of subjects reported upon here will not permit a comparison of cardiac metabolism in 
different pathologic states. On the other hand, in the absence of significant after-loading (47), evidence of anoxia $(27,28)$, or cardiac failure $(47)$, the data presented probably represent an approximation of normal resting cardiac metabolism. Of particular interest was subject T. F., who experienced mild anginal pain and produced lactate during the study. This patient demonstrated a low FFA uptake based on FFA- ${ }^{14} \mathrm{C}$ fractional extraction and a high fractional oxidation. FFA did not appear to be preferentially esterified as suggested by work with the acutely anoxic dog by one of the authors (45) and the perfused rat heart (11). The degree of ischemia encountered during angina in human subjects may not be sufficient to impose such a change in FFA metabolism by the myocardium. The relatively high glucose extraction noted in T. F. was consistent with previous observations (48) but was equaled by other nonlactate-producing subjects. It should also be noted that the cardiac extractions of $\beta$-hydroxybutyrate and acetoacetate in this subject did not differ markedly from the findings for the other subjects. This confirms a previous single observation (49) that a shift in equilibrium in the lactate dehydrogenase reaction during spontaneous angina is not necessarily associated with a similar shift in the $\beta$-hydroxybutyrate dehydrogenase system.

\section{ACKNOWLEDGMENTS}

We are grateful to Miss Elizabeth Ferris for her invaluable liaison and technical assistance. Steven Safe, Ph.D., and Ronald Harris, Ph.D., performed the GLC determinations (Harvard University, Department of Chemistry). We also thank Dr. George Cahill for his encouragement and support.

This work was supported in part by U. S. Public Health Service Grants 5-R01-HE 08591, 5-T01-HE 05679, 1-P01HE 11306, and HE-06216; U. S. Public Health Service Contract No. PH-43-67-1439; Kriendler Memorial Foundation; Women's Aid for Heart Research, Boston, Mass.; Muscular Dystrophy Associations of America, Inc., The American Medical Association Education and Research Foundation, and the New York Heart Association. Dr. Gorlin is an Investigator, Howard Hughes Medical Institute. Dr. Brachfeld is a recipient of Career Development Award HE-07521 from the National Heart Institute, and Career Scientist of the Health Research Council of the City of New York (Grant No. 1-243).

\section{REFERENCES}

1. Bing, R. J., A. Siegel, I. Ungar, and M. Gilbert. 1954. Metabolism of the human heart. II. Studies on fat, ketone and amino acid metabolism. Amer. J. Med. 16: 504.

2. Gordon, R. S. Jr., and A. Cherkes. 1956. Unesterified fatty acid in human blood plasma. J. Clin. Invest. 35: 206.

3. Carlsten, A., B. Hallgren, R. Jagenburg, A. Svanborg, and L. Werko. 1961. Myocardial metabolism of glucose, lactic acid, amino acids and fatty acids in healthy human individuals at rest and at different work loads. Scand. J. Clin. Lab. Invest. 13: 418.

4. Rothlin, M. E., and R. J. Bing. 1961. Extraction and release of individual free fatty acids by the heart and fat depots. J. Clin. Invest. 40: 1380.
5. Harris, P., C. Chlouverakis, J. Gloster, and J. Howel Jones. 1962. Arteriovenous differences in the composition of plasma free fatty acids in various regions of the body. Clin. Sci. 22: 113.

6. Doll, E., J. Keul, H. Steim, C. Maiwald, and H. Reindell. 1965. Uber den Stoff wechsel des menschlichen Herzens, II. Pfluegers Arch. Gesamte Physiol. Menschen Tiere. 282: 28.

7. Willebrands, A. F. 1964. Myocardial extraction of individual nonesterified fatty acids, esterified fatty acids and acetoacetate in the fasting human. Clin. Chim. Acta. 10: 435.

8. Bernsmeier, A., and W. Rudolph. 1965. Die Fettsäuren im Stoffwechsel des Herzmuskels. Deut. Med. Wochenschr. 90: 743.

9. Goodale, W. T., R. E. Olson, and D. B. Hackel. 1959. The effects of fasting and diabetes mellitus on myocardial metabolism in man. Amer. J. Med. 27: 212.

10. Carlsten, A., B. Hallgren, R. Jagenburg, A. Svanborg, and L. Werkö. 1963. Myocardial arteriovenous differences of individual free fatty acids in healthy human individuals. Metabolism. 12: 1063.

11. Evans, J. R. 1964. Importance of fatty acid in myocardial metabolism. Circ. Res. 15 (Suppl. 2) : 96.

12. Havel, R. J., B. Pernow, and N. L. Jones. 1967. Uptake and release of free fatty acids and other metabolities in the legs of exercising men. J. Appl. Physiol. 23: 90.

13. Hagenfeldt, L., and J. Wahren. 1968. Human forearm muscle metabolism during exercise. II. Uptake, release and oxidation of individual FFA and glycerol. Scand. J. Clin. Lab. Invest. 21: 263.

14. Ross, R. S., K. Ueda, P. R. Lichtlen, and J. R. Rees. 1964. Measurement of myocardial blood flow in animals and man by selective injection of radioactive inert gas into the coronary arteries. Circ. Res. 15: 28.

15. Dole, V. P., and H. Meinertz. 1960. Microdetermination of long-chain fatty acids in plasma and tissues. J. Biol. Chem. 235: 2595.

16. Trout, D. L., E. H. Estes, Jr., and S. J. Friedberg. 1960. Titration of free fatty acids of plasma: study of current methods and a new modification. J. Lipid Res. 1: 199.

17. Van Handel, E., and D. B. Zilversmit. 1957. Micromethod for direct determination of serum triglycerides. J. Lab. Clin. Med. 50: 152.

18. Folch, J., M. Lees, and C. H. Sloane Stanley. 1957. A simple method for the isolation and purification of total lipids from animal tissues. J. Biol. Chem. 226: 497.

19. Goldrick, B., and J. Hirsch. 1963. A technique for quantitative recovery of lipid from chromatoplates. J. Lipid Res. 4: 482.

20. Van Slyke, D. D., and J. M. Neil. 1924. Determination of gases in blood and other solutions by vacuum extraction and manometric measurement. J. Biol. Chem. 61: 523 .

21. Seligson, D., and K. Hirahara. 1957. The measurement of ammonia in whole blood, erythrocytes and plasma. J. Lab. Clin. Med. 49: 962.

22. Horn, H. D., and F. H. Bruns. 1956. Quantitative Bestimmung von $\mathrm{L}(+)$-Milchsäure mit Milchsauredehydrogenase. Biochim. Biophys. Acta. 21: 378.

23. Hoffman, W. S. 1937. Rapid photoelectric method for the determination of glucose in blood and urine. J. Biol. Chem. 120: 51. (As modified by Technicon AutoAnalyzer Methodology N-2b). 
24. Williamson, D. H., J. Mellanby, and H. A. Krebs. 1962. Enzymic determination of D (-)- $\beta$-hydroxybutyric acid and acetoacetic acid in blood. Biochem. J. 82: 90.

25. Bergmeyer, H. V. 1963. Methods of Enzymatic Analysis. Academic Press Inc., New York.

26. Snedecor, G. W. 1956. Statistical methods. The Iowa State University Press, Ames.

27. Krasnow, N., W. A. Neill, J. V. Messer, and R. Gorlin. 1962. Myocardial lactate and pyruvate metabolism. $J$. Clin. Invest. $41: 2075$.

28. Cohen, L. S., W. C. Elliott, M. D. Klein, and R. Gorlin. 1966. Coronary heart disease: clinical cinearteriographic and metabolic correlations. Amer. J. Cardiol. 17: 153.

29. Gousios, A. G., J. M. Felts, and R. J. Havel. 1967. Effects of ouabain on force of contraction, oxygen consumption, and metabolism of free fatty acids in the perfused rabbit heart. Circ. Res. 21: 445.

30. Evans, J. R., L. H. Opie, and J. C. Shipp. 1963. Metabolism of palmitic acid in perfused rat heart. Amer. J. Physiol. 205: 766.

31. Kikuchi, T., S. Endo, T. Kishü, Y. Hasegawa, Y. Ito, and T. Kobayashi. 1966. Myocardial metabolism of individual free fatty acids (FFA) in valvular disease as compared with coronary sclerosis. Jap. Heart J. 7: 130.

32. Walmsley, T. 1929. The heart. In Quain's Elements of Anatomy. Longmans Green \& Co., Ltd. London. 11th edition. Vol. 4. Part III. 25.

33. Balsaver, A. M., A. R. Morales, and F. W. Whitehouse. 1967. Fat infiltration of myocardium as a cause of cardiac conduction defect. Amer. J. Cardiol. 19: 261.

34. Stein, O., and Y. Stein. 1968. Lipid synthesis, intracellular transport, and storage. III. Electron microscopic radio-autographic study of the rat heart perfused with tritiated oleic acid. J. Cell Biol. 36: 63.

35. Delcher, H. K., M. Fried, and J. C. Shipp. 1965. Metabolism of lipoprotein lipid in the isolated perfused rat heart. Biochim. Biophys. Acta 106: 10.

36. Muir, J. R. 1968. The regional production of lipoprotein lipase in man. Clin. Sci. 34: 261.
37. Ballard, F. B., W. H. Danforth, S. Naegle, and R. J. Bing. 1960. Myocardial metabolism of fatty acids. $J$. Clin. Invest. 39: 717.

38. Gousios, A., J. M. Felts, and R. J. Havel. 1963. The metabolism of serum triglycerides and free fatty acids by the myocardium. Metabolism. 12: 75 .

39. Robinson, J., and E. A. Newsholme. 1967. Glycerol kinase activities in rat heart and adipose tissue. Biochem. J. 104 : 2C.

40. Luck, J. M. 1949. The combination of fatty acid anions with proteins. Faraday Soc. Trans. 6: 44.

41. Goodman, DeW. S. 1958. The interaction of human serum albumin with long chain fatty acid anions. J. Amer. Chem. Soc. 80: 3892.

42. Evans, J. R. 1964. Cellular transport of long chain fatty acids. Can. J. Biochem. 42: 955.

43. Spitzer, J. J., and M. Gold. 1965. Studies on the metabolism of free fatty acids in diabetic and fasting dogs. Ann. N. Y. Acad. Sci. 131: 235.

44. Havel, R. J., L. A. Carlson, L. G. Ekelund, and A. Holmgren. 1964. Turnover rate and oxidation of different free fatty acids in man during exercise. J. Appl. Physiol. 19: 613.

45. Scheuer, J., and N. Brachfeld. 1966. Myocardial uptake and fractional distribution of palmitate $1-C^{16}$ by the ischemic dog heart. Metabolism. 15: 945.

46. Carlsten, A., B. Hallgren, R. Jagenburg, A. Svanborg, and L. Werkö. 1966. Amino acids and free fatty acids in plasma in diabetes. II. The myocardial arteriovenous differences before and after insulin. Acta. Med. Scand. 179: 631 .

47. Wittels, B., and J. F. Spann, Jr. 1968. Defective lipid metabolism in the failing heart. J. Clin. Invest. 47: 1787.

48. Brachfeld, N., and J. Scheuer. 1967. Metabolism of glucose by the ischemic dog heart. Amer. J. Physiol. 212: 603.

49. Rudolph, W., L. Meixner, and H. G. Künzig. 1967. Pharmakodynamische Beeinflussung von Coronardurchblutung und Stoffwechel des menschlichen Herzens. Klin. Wochenschr. 45: 333. 